\title{
Amor, amizade e valimento na linguagem cortesã do Antigo Regime*
}

Ricardo de Oliveira ${ }^{* *}$

Na cultura política do Ancien Régime, as relações pessoais eram fatores determinantes para qualquer projeto ascensional. Numa sociedade regulada pela lógica do favorecimento pessoal, privar da amizade e do afeto de alguém mais poderoso e superior tornava-se a priori o elemento mais significativo para quem possuía ambições políticas. Neste quadro, emergiu a figura emblemática do chamado valido, alguém que, por ocupar o centro da afetividade régia, podia influenciar e atuar decisivamente no cenário político. Os casos mais conhecidos são os dos Duques de Lerma e de Olivares, na Espanha, do Duque de Buckingham, na Inglaterra, dos Cardeais Richelieu e Mazarino, na França, do Conde Castelo Melhor e do Marquês de Pombal, em Portugal. Este artigo pretende discutir algumas questões conceituais mais significativas deste aspecto importante da cultura política do Ancien Régime.

Palavras-chave: Cultura política - Valido - Sociedade de Corte

Love, Friendship and Favoritism in the Courtier Language of the Old Regimen

In the political culture of the Ancien Régime, personal relations were a key factor for any project of social mobility. In a society regulated by the logic of personal aid, to deprive someone of friendship and the affection of someone superior or more powerful, has became, a priori, the most important element for those who had political ambitions. The emblematic figure of the valido, who has occupied the center of regal affectivity,

\footnotetext{
*Artigo recebido em abril de 2005 e aprovado para publicação em abril de 2006.

**Doutor pelo PPGHIS/UFRJ e Professor do Curso de História da Universidade Federal Rural do Rio de Janeiro. E-mail: rdoclio@uol.com.br.
} 
from where he could influence and act in the political scene. The Dukes of Lerma and Olivares, in Spain; the Duke of Buckingham, in England; Cardinals Richelieu and Mazarino, in France; the Conde Castelo Melhor and Marquis of Pombal, in Portugal are exemplars cases. This article intends to propose some significant conceptual questions about this important aspect of the Ancien Régime political culture.

Keywords: Political culture - Valido - Court Society

Amour, amitié et favoritisme dans le langage courtisan de l'Ancien Régime Dans la culture politique de l'Ancien Régime, les relations personnelles étaient facteur déterminant pour tous les projets d'ascension. Dans une société réglée par la logique de la faveur personnelle, le fait de compter sur l'amitié et l'affection de quelqu'un plus puissant et supérieur était l'élément le plus significatif pour celui qui possédait des ambitions politiques. Dans ce cadre, on constate l'émergence de la figure emblématique du valido: quelqu'un qui, du fait d'occuper le centre de l'affection royale, pouvait influencer et agir décisivement dans le scénario politique. Les cas les plus connus sont ceux des Ducs de Lerma et d'Olivares, en Espagne, du Duc de Buckingham, en Angleterre, des Cardinaux de Richelieu et Mazarin, en France, du Comte Castelo Melhor et du Marquis de Pombal, au Portugal. Cet article vise à discuter quelques questions conceptuelles significatives de cet aspect important de la culture politique de l'Ancien Régime.

Mots-clefs: Culture politique - Valido - Société de Cour

Em 1635, ainda sob o drama da Guerra dos Trinta Anos, Don Gaspar de Gusmán, Conde-Duque de Olivares (1587-1645), vivia o momento pleno de seu valimento junto ao Rei de Espanha, Felipe IV. Na ocasião, a Corte de Madri estava agitada com os preparativos finais que envolviam a construção do Palacio del Retiro, el Buen Retiro del Rey, obra em cuja condução Olivares se empenhou como nunca. Uma das maiores expectativas que se tinha girava em torno da decoração del Salón de Reinos, totalmente idealizado por Olivares. Era fato comum nas monarquias européias do Antigo Regime conceder à decoração de seus palácios uma dimensão simbólica sempre relevante, através da qual se objetivava celebrar a memória, as glórias e as grandezas da dinastia reinante. A pedido de Olivares, a seqüência principal de quadros que compunha a decoração del Salón foi criada pelo pintor andaluz Diego Rodriguez Silva y Velásquez (1599-1660), seu protegido, e compreendia uma série de retratos eqüestres de Felipe III, de Felipe IV, de suas esposas e do Príncipe Balthasar Carlos, herdeiro do trono. Num segundo plano decorativo, foram posicionados 
quadros que festejavam as vitórias das armas espanholas nos diversos conflitos vivenciados na época. Dentre as representações desses triunfos, havia uma que pode ser considerada emblemática: o quadro pintado pelo Frei Juan Bautista Maino (1581-1649), Recuperación de Bahia en 1625, provavelmente feito entre os anos de 1634 e 1635. Nele, o jogo de imagens remetia a uma dupla mensagem simbólica, cujos significados são interessantes para refletirmos a respeito da questão do valimento durante o Antigo Regime, pois, em um plano simbólico superior, posto à direita do observador, há um retrato de corpo inteiro del Rey Felipe IV, jovem e demonstrando demasiada insegurança. Ele está, por sua vez, rodeado, à direita, pela Deusa Minerva e, à esquerda, surpreendentemente, pelo próprio Conde-Duque de Olivares que, com sua mão esquerda, segura uma espada e, com a direita, sustenta, sobre a cabeça do Rei, o símbolo da vitória, numa alegoria explícita ao triunfo da própria monarquia. ${ }^{1}$

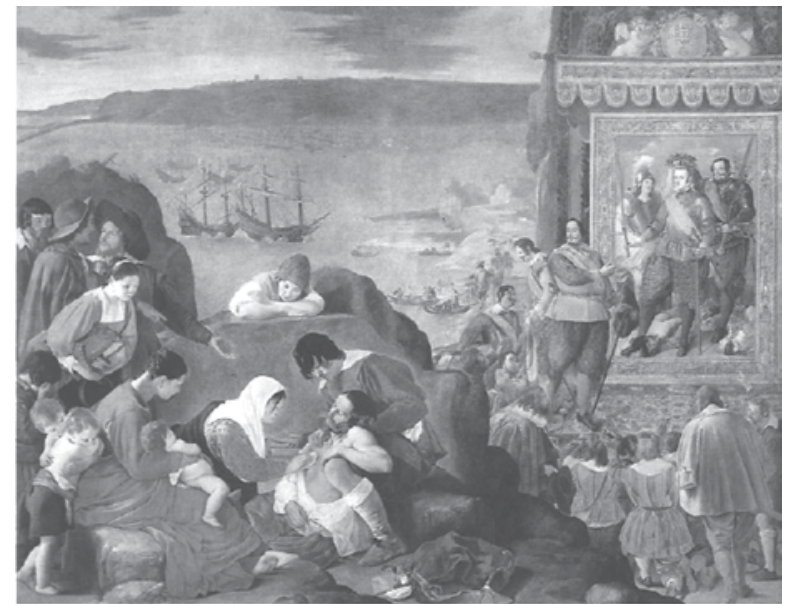

Recuperación de Bahia en 1625, finalisado entre 1634-1635, de Frei Juan Bautista Maino (1581-1649). Óleo sobre tela, Museu do Prado, Madri.

Esta justaposição de imagens e a mensagem que ela expressa talvez não possuam paralelo na história da pintura do Antigo Regime, ${ }^{2}$ pois se evidenciava o caráter de ascendência sobre o jovem monarca que possuía, então,

\footnotetext{
${ }^{1}$ Ver John H. Elliott, Richelieu y Olivares, Barcelona, Crítica, 1995, p. 47-48. , Jonathan Browm, Un Palacio para el Rey. El Buen Retiro y la Corte de Felipe IV, Madri, Taurus, 2003, p. 6 e segs.

${ }^{2}$ Jonathan Brown, "Peut-on assez louer cet excellent ministre? Imágenes del privado en Inglaterra, Francia y España”, J. H. Elliott, Laurence Brockliss (orgs.), El Mundo de Los Validos, Madri, Taurus, 1999, p. 321-337.
} 
Olivares - valido e favorito Ministro de Estado e um dos homens mais poderosos da Europa de seu tempo. Naquele momento, tornava-se explícito que Olivares gozava da centralidade do afeto e da amizade do rei. Contudo, ele não foi o único a vivenciar a experiência de monopólio do favoritismo régio, desfrutando de seu amor e amizade. Mas o que era ser um valido, privado ou favorito no âmbito da cultura política daquela época? Quais os significados que as questões relacionadas aos afetos tinham para a vida política e social? De que maneira, naquela linguagem política, ocorreu o encontro entre os conceitos de amor, amizade e valimento? Responder a algumas destas perguntas será o propósito deste artigo.

No entanto, antes de tentarmos responder a estas questões, é importante que se parta da premissa de que as sociedades do Antigo Regime devem ser compreendidas como outro continente cultural, uma outra dimensão antropológica. E, neste outro lugar, estes conceitos possuíam significados distintos dos que informam a nossa cultura. Neste sentido, seguindo em parte o método da chamada Begriffsgeschichte, devemos desnaturalizar estes vocábulos apreendendo-os em sua historicidade. Para tanto, conforme postulou Reinhart Koselleck, há que se operar tanto a partir do contexto lingüístico específico quanto daquilo que seria extralingüístico, ${ }^{3}$ pois as palavras não possuem um significado em si mesmas.

Partindo desta premissa teórica, metodologicamente, destacamos, para compreendê-los, os significados que os conceitos de amor, amizade e valimento possuíam na linguagem política do Antigo Regime, fazendo uso intenso de alguns léxicos, vocabulários e dicionários produzidos entre os séculos XVI e XVIII. E é importante assinalar que estas fontes são essenciais para qualquer investigação sobre a linguagem e a cultura política do Antigo Regime, pois, dentre outras coisas, elas são verdadeiras "radiografias" da teia de significados que constituía aquela sociedade. Faremos uso, por exemplo, do Ditionarium Latino-Lusitanum, ${ }^{4}$ do Pe. Jerônimo Cardoso, de 1562, do Thresor de la Langue Françoyse tant Ancienne que Moderne, ${ }^{5}$ de Jean Nicot, obra publicada em 1606 e cuja importância para a constituição da língua francesa é inquestionável,

\footnotetext{
${ }^{3}$ Reinhart Koselleck, Futuro Pasado. Por la semántica de los tiempos históricos, Barcelona, Paidós, 1993, p. 107 e segs.

${ }^{4}$ Jerônimo Cardoso, Dictionarium Latino-Lusitanicum, et Lusitanico-Latinum (1 ${ }^{\text {a }}$ ed., 1569), Lisboa, Officcina Larrentij de Anueres, 1643.

${ }^{5}$ Jean Nicot, Thresor de la Langue Françoyse, tant Ancienne que Moderne, Paris, David Douceur, 1606.
} 
pois foi a síntese dos dicionários publicados no século anterior por Robert Estienne. Também desta mesma época, o Tesoro de la Lengua Castellana o Española ${ }^{6}$ (1611), de Sebastián de Covarrubias, obra de enorme significado para a cultura ibérica da época, e o léxico de fundamental importância para a construção da língua italiana contemporânea, o Vocabolario Degli Accademici Della Crusca, ${ }^{7}$ publicado em 1612, serão importantíssimos em nossa abordagem. Para a língua portuguesa, recorreremos ao Thesouro da Lingoa Portuguesa,${ }^{8} \mathrm{do}$ Pe. Bento Pereira, publicado em 1647.

Todavia, são as obras que datam do final do século XVII e do início do XVIII que nos interessarão de forma mais sistemática. O polêmico Dictionnaire Universel, contenant généralement tous les mots français tant vieux que modernes, \&̊ les termes de toutes les sciences \&̊ les arts (1690), ${ }^{9}$ de Antoine Furetière, além do Dictionnaire de L'Academie Française ${ }^{10}$ (1694) e do Dictionnaire Universel Français et Latin, mais conhecido como Dictionnaire de Trevoux ${ }^{11}$ (1721), constituem referências importantes para nossa reflexão. Porém, destacamos que, para o universo ibérico do século XVIII, faremos uso intenso do Vocabulário Português \& Latino, ${ }^{12}$ do Pe. Raphael Bluteau, obra que consideramos fundamental para a compreensão do universo áulico do Antigo Regime português, e do Diccionario de la Lengua Castellana, ${ }^{13}$ composto pela Real Academia, publicado entre 1726 e 1736, mais conhecido como Diccionario de Autoridades. Em seu conjunto,

\footnotetext{
${ }^{6}$ Sebastián de Covarrubias, Tesoro de la Lengua Castellana o Española (1 ${ }^{\mathrm{a}}$ ed., 1611), Barcelona, Editorial Alta Fulla, 1998.

${ }^{7}$ Vocabolario Degli Accademici Della Crusca (1 $1^{a}$ ed., 1612), Nápoles, a spesse di Giuseppe Ponzelli, nella Stamperia di Giovanni di Simone, 5 Vols., 1746.

${ }^{8}$ Pe. Bento Pereira, Thesouro da Lingoa Portuguesa, Lisboa, Paulo Craesbeeck, 1647.

${ }^{9}$ Antoine Furetière, Dictionnaire Universel, contenant généralement tous les mots français tant vieux que modernes, \& les termes de toutes les sciences \& les arts, Le Haye Rotterdam, Arnout \& Reinier Leers, 3 Tomes, 1690.

${ }^{10}$ Dictionnaire de L'Academie Française, Paris, Jean Baptiste Coignard, 4 Vols., 1694.

${ }^{11}$ Dictionnaire Universel Français et Latin, Paris, 7 Vols., 1740.

${ }^{12}$ Pe. Raphael Bluteau, Vocabulário Português \&̇ Latino, Coimbra, Colégio das Artes da Companhia de Jesus, 10 Vols., 1712-1728. A ordem em que foram publicadas as diversas partes da obra é a seguinte: os tomos I (A) e II (B e C) foram publicados em 1712; os tomos III (D e E), IV (F e G) e V (H e J), em 1713; o tomo VI (K, L, M), em 1716; o tomo VII (O e P), em 1720; o tomo VIII (K, R e S), em 1720; o tomo IX (T, U, V, X e Z - há ainda neste tomo um pequeno dicionário castelhano-português também de autoria do Pe. Bluteau), em 1721; e, por último, o tomo X, em 1728, que compreende um suplemento importante para o conjunto da obra.

${ }^{13}$ Real Academia Española, Diccionario de la Lengua Castellana, Madri, En la Impresora de Francisco Hierro, 6 Vols., 1726-1739.
} 
estas obras são, como dissemos, significativas "radiografias" da linguagem que se configurava em diferentes cortes do Antigo Regime.

Assim, cremos que seja fundamental para a compreensão do fenômeno do valimento, no âmbito da cultura política do Antigo Regime, perceber que a problemática dos afetos e das relações de amizade, como elementos inerentes aos códigos culturais daquela sociedade, possuía sentidos e dimensões específicas. Pode-se dizer que o amor e a amizade eram vistos como elementos essenciais para a construção de laços societários e das formas de normatização da vida comunitária, possuindo uma dimensão social real e profundamente enraizada na vida cotidiana, algo que ultrapassava o nível do discurso racionalmente conduzido, estando no cerne da constituição da própria sociedade. ${ }^{14}$ Neste sentido, a possibilidade ou não de ter acesso direto ao núcleo do poder ou mesmo de se ter êxito na tentativa de alcançar certa mobilidade social ascensional derivava, em larga medida, da qualidade das relações que cada aspirante possuía. Nessa sociedade, a lógica e o princípio do mérito pouco ou nada valiam, ser amigo de alguém poderoso e, mais do que tudo, ser amigo do rei tornavam-se o elemento decisivo para qualquer trajetória social. $\mathrm{O}$ valido era, portanto, alguém que, através de lutas e disputas inerentes ao universo da corte, conseguia galgar posições e ocupar a centralidade do afeto régio, monopolizando o amor, a amizade e a graça.

Ao contrário do que ocorre com a moderna oposição entre razão e emoção, o amor e os afetos como elementos normatizadores da vida no Antigo Regime não se restringiam à dimensão da sexualidade ou da intimidade dos casais. Pelo contrário, a compreensão que se tinha na época dos laços amorosos, quando relacionados a significados de conotação sexual, era muito negativa. Exemplo disto de que estamos tratando é possível encontrar em discursos das mais variadas naturezas: em textos políticos, filosóficos, jurídicos ou teológicos, sendo que, naquelas sociedades, estas eram dimensões discursivas que se atravessavam mutuamente.

Em 1611, Sebastián de Covarrubias, em seu Tesoro, dizia: amores siempre se toma por mala parte, por los amores lascivos, que son los que tratan los enamorados. ${ }^{15} \mathrm{Um}$ século mais tarde, o Pe. Raphael Bluteau legou-nos uma compreensão ainda mais ampla do entendimento que se tinha naquela época sobre o papel

${ }^{14}$ Anthony Guiddens, A Constituição da Sociedade, São Paulo, Martins Fontes, 2003, p. 3 e segs.

${ }^{15}$ Sebastián de Covarrubias, "Amor”, op. cit., p. 113. 
do amor como elemento de constituição da sociedade. Antes de qualquer coisa, Bluteau assinalou que o amor se relacionava com Deus e sua ação criadora tinha como finalidade reger o destino dos homens. E, mais significativo ainda, dizia Bluteau, o amor preside o ordenamento das relações humanas, porque, "no homem, o amor he uma inclinação da vontade para o que lhe parece bem, ou por via de entendimento, que assim o julgue, ou pellas potencias, \& sentidos externos, que assim o representa". ${ }^{16}$ Desta forma, o amor funcionaria como elemento de coesão social. Assim, outras formas de amor seriam: o "amor de complacência", isto é, o querer e o desejar bem ao próximo; o "amor de benevolência", ou seja, o que envolve a partilha e a comunhão; o "amor devotionis", referente ao sacrifício que envolve a relação entre os homens e a divindade e, por último, o "amor conjugal", que existe entre marido e mulher. Estas, em suma, seriam as verdadeiras formas de amor. Por outro lado, Bluteau condenava tanto o "amor de concupiscência" quanto o "amor próprio", o qual equivale a egoísmo e individualismo. Da mesma forma, reprova "o amor ilícito e profano", relacionado ao apego a bens materiais, à luxúria e à sexualidade. ${ }^{17}$

O discurso em torno do amor, conforme defende o historiador Pedro Cardim, "tinha enormes responsabilidades na ordenação" do que poderíamos denominar "espaço público". ${ }^{18}$ Devemos perceber ainda que a preocupação com os significados do amor na cultura política do Antigo Regime está longe de ser algo fora de propósito ou menor. Na verdade, em termos empíricos, existe uma quantidade grande de documentos (políticos, teológicos, epistolares, econômicos, etc.) em que o amor e a amizade são elementos-chave, e não meros adornos de linguagem, no processo de construção da sociedade, ${ }^{19}$ notadamente no mundo ibérico. Assim, as relações sociais eram constituídas por laços, por assim dizer, "amorosos". De maneira substantiva, enfatiza Cardim:

(...) o que é mais significativo é que essa influência estruturante da leitura afetiva das relações comunitárias sobreviveu ao desenvolvimento da economia mercantil e financeira. De fato, a conviç̧ão de que o corpo social assentava em laços de amor revelou uma longevidade verdadeiramente ímpar. ${ }^{20}$

\footnotetext{
${ }^{16}$ Raphael Bluteau, "Amor”, op. cit., Tomo I, 1712, p. 345.

${ }^{17}$ Idem, p. 345-346.

${ }^{18}$ Pedro Cardim, O Poder dos Afetos. Ordem amorosa e dinâmica política no Portugal do Antigo Regime, Lisboa, Universidade Nova de Lisboa, 2000 (Tese de Doutoramento), p. 6-7.

${ }^{19}$ Idem, p. 12.

${ }^{20} \mathrm{Ibid}$, p. 315.
} 
$\mathrm{Na}$ linguagem política do Antigo Regime, tal como o amor é inerente à sua enunciação discursiva, o conceito de amizade assentava-se sobre um ethos que fundamentava princípios normatizadores da vida social, econômica e política. Aquilo que imaginamos como res publica possuía, no discurso sobre os afetos, os elementos constituintes da sociedade. O ideal do bem comum, isto é, o elemento essencial na constituição daquela sociedade, encontrava na estrutura relacional da amizade sua configuração mais bem acabada. ${ }^{21}$ A crença mais arraigada na tradição cultural do mundo ibérico era a de que a sociedade se organizava a partir de uma espécie de "constituição natural", ou seja, a posição de cada um no corpo social era ditada por uma compreensão de que tudo fora criado e naturalmente organizado por um ato divino, cabendo aos homens aceitar as coisas como elas se apresentavam. ${ }^{22}$

Partindo de uma compreensão de que a natureza humana era essencialmente reconhecível pela sua propensão para a bondade, a função maior tanto da comunidade política quanto da familiar era zelar pelo bem comum, a partir do que havia sido postulado por Aristóteles na Política e sacralizado pelo tomismo, séculos mais tarde. ${ }^{23}$ Neste sentido, todos os membros da comunidade deveriam cuidar da realização deste princípio básico e zelar por ele. ${ }^{24}$ Esta concepção sobre a constituição da sociedade se fundamentava no

\footnotetext{
${ }^{21}$ A tese de Pedro Cardim é importante referência no que tange à compreensão sobre a dinâmica da cultura política do Antigo Regime português, em particular nas questões relativas à constituição societária que teve, na semântica dos afetos e seus fundamentos. Porém, são importantes ainda para demonstrar a historicidade da questão os seguintes estudos: Phillipe Áries, L'enfantet la viefamiliale sous L'Ancièn Regime, Paris, Seuil, 1961; Roger Chartier, História da Vida Privada. Da Renascença ao Século das Luzes, São Paulo, Companhia das Letras, Vol. 3, 2002; Richard Sennet, O declínio do homem público. As tramas da intimidade, São Paulo, Companhia das Letras, 1999; Niklas Luhmann, O Amor como paixão. Para a codificação da intimidade, Lisboa, Difel, 1991; Anthony Giddens, A Transformação da Intimidade. Sexualidade, Amor e Erotismo nas Sociedades Modernas, São Paulo, Unesp, 1993.

${ }^{22}$ Sobre este assunto, ver Pedro Cardim, O Poder dos Afetos, op. cit., p. 28 e segs.

${ }^{23}$ São Tomás de Aquino certamente escreveu o mais importante comentário medieval à obra de Aristóteles, In Libros Politicorum Aristotelis expositio, tornando-se a fonte básica de acesso à obra do filósofo grego pela cristandade ocidental. Em 1584, Pedro Simon Abril fez a primeira tradução para o castelhano, com o título Los ocho libros de república Del filósofo Aristóteles, con unos breves y provechosos comentarios para todo género de gentes y particularmiente para los que tienen cargo de público gobierno. Usamos aqui a edição crítica espanhola mais recente, traduzida por Manuela Garcia Valdes, Aristoteles. Política, Madri, Gredos, 1999.

${ }^{24}$ Para uma análise ampla da questão, ver Quentin Skinner, Los Fundamentos del Pensamiento Político Moderno, México, Fondo de Cultura Económica, 2 Vols., 1993. (Há versão portuguesa da obra; ver Quentin Skinner, As Fundações do Pensamento Político Moderno, São Paulo, Companhia das Letras, 1994.)
} 
chamado paradigma corporativista, que postulava a "indispensabilidade de todos os órgãos da sociedade", ou seja, "a impossibilidade de um poder político puro e não partilhado". ${ }^{25}$ Assim, o poder era, por natureza, "repartido". E, em uma sociedade bem governada, este princípio deveria traduzir-se em autonomia jurídico-política dos corpos sociais, embora tal autonomia nunca fosse pensada como uma força capaz de destruir a hierarquia natural de funções que o corpo social possuía, pois não se questionava a primazia da cabeça (caput) como guia de todo o corpo. A sua função era a de resguardar a autonomia dos corpos sociais, promovendo a harmonia entre os seus membros e praticando a justiça. Desta maneira, manter a ordem social significava perpetuar a cabeça e os demais membros do corpo no lugar adequado e objetivamente estabelecido. ${ }^{26}$

Em Portugal, a durabilidade desta visão é notável. Naquele período, a concepção corporativista da sociedade, como assinalaram Ângela Xavier Barreto e António Manuel Hespanha, introduziu "importantes limitações ao poder real, advindo daí importantes conseqüências jurídicas e institucionais", pois "de fato, uma vez que a doutrina corporativa do poder estabelecia como núcleo dos deveres do rei o respeito da justiça, este ficava obrigado a observar o direito" em suas diversas instâncias. ${ }^{27}$ Por outro lado, no mundo ibérico, o denominado paradigma individualista, apesar de ter conhecido algumas formulações, não conheceu muita fortuna, pelo menos até o final do século XVII. De maneira semelhante, o providencialismo, que concebeu o poder como produto livre da vontade de Deus, cujos pensadores mais notáveis foram, dentre outros, Jean Bodin (1530-1596) e Jacques-Benigne Bossuet (1627-1704), também foi recebido com muitas ressalvas no mundo ibérico. Por sua vez, o conjunto de teorias de caráter contratualista, que concebeu como irreversível a transferência de poder e dos direitos naturais da sociedade para o soberano, tendo no pensamento de Thomas Hobbes (1588-1679), particularmente o exposto no Leviathan (1651) o seu melhor exemplo, praticamente não se fez presente em Portugal. ${ }^{28}$

\footnotetext{
${ }_{25}$ Ângela Barreto Xavier, António Manuel Hespanha, "A representação da Sociedade e do Poder", José Mattoso (dir.), António Manuel Hespanha (coord.), História de Portugal. O Antigo Regime (1620-1807), Lisboa, Estampa, 1992, p. 123.

${ }^{26}$ Idem, p. 123.

${ }^{27}$ Ibid, p. 129-130.

${ }^{28}$ Ibidem, p. 130 e segs.
} 
O pensamento político católico que se hegemonizou na Península Ibérica no período, ao condenar o pragmatismo amoral derivado das formulações de Maquiavel, ${ }^{29}$ fez com que surgisse uma espécie de pragmatismo católico, que deveria estar atento aos condicionalismos do momento. Esta concepção teve no chamado tacitismo ${ }^{30}$ muito divulgado em Portugal e na Espanha através de Justo Lipsio, ${ }^{31}$ sobretudo na obra Policorum sive civilis doctrinae libri sex, qui ad principatum maxime spectant, publicada pela primeira vez em 1589, uma de suas formulações mais importantes. Com este mesmo sentido, a obra de Giovanni Botero, ${ }^{32}$ Della Ragione di Stato, publicada na Itália no mesmo ano, amplamente divulgada no mundo ibérico, foi também importante na divulgação do que estamos chamando de pragmatismo católico. ${ }^{33}$ Estes autores, ao refletirem sobre a natureza do poder político, produziram significativas avaliações acerca do papel que os favoritos tinham na esfera mais íntima da governação do reino.

Mas, retomando a análise sobre a questão da amizade e dos afetos, que, como falamos, na cultura política do Antigo Regime Ibérico se configuravam como elementos decisivos no que se refere à problemática do valimento, visto que o caráter público dos gestos afetivos tinha sérias implicações políticas, pois,

${ }^{29}$ Ver José Antonio Maravall, "Maquiavelo y Maquiavelismo en España”, Estudios de Historia del Pensamiento Español. El Siglo del Barroco, Madri, Ediciones Cultura Hispánica, Vol. III, 1984, p. 39-71.

${ }^{30}$ Perter Burke, "L’influence de Tacite, le scepticisme et la raison d'État", James Henderson Burns (dir.), Histoire de la Pensée Politique Moderne, Paris, Presses Universitaire de France, 1997, p. 440-445; José Antonio Maravall, "La corriente doctrinal del tacitismo en España”, Estudios de História del Pensamiento Español, op. cit., p. 73-97.

${ }^{31}$ Muito influente na Península Ibérica, Justo Lipsio (1547-1606) foi responsável pela edição das obras de Tácito, em 1574. Tornou-se a principal referência do chamado neoestoicismo em fins do século XVI. Além da citada Politicorum, traduzida para o castelhano por Bernardino de Mendonza e publicada em 1604, De Constantia, de 1583, um guia para os tempos de intolerância religiosa que conheceu cerca de oitenta edições em menos de um século, e $D e$ Mitia Romana, de 1595, são as referências fundamentais para a obra política de Lipsio. Sobre a importância da sua obra em Portugal e Espanha, ver Martim Albuquerque, Um percurso da Construção ideológica do Estado.A Recepção lipsiana em Portugal:estoicismo e prudência política, Lisboa, Quetzal Editores, 2002, e Luis Reis Torgal, Ideologia Política e Teoria do Estado na Restauração Portuguesa, Coimbra, Biblioteca Geral da Universidade, 2 Vols., 1981-1982; José António Maravall, Teoria del Estado, op. cit.

${ }^{32}$ De origem italiana, Giovanni Botero (1544 -1617) foi um dos principais pensadores políticos católicos do século XVI. Além da obra Della Ragione di Stato, de 1589, destacam-se Delle cause della grandeza a delle cittá, de 1588, e a famosa Relazioni Universali, publicada entre 1592 e 1596.

33 Ângela Barreto Xavier, António Manuel Hespanha, "A representação da Sociedade e do Poder", op. cit., p. 133. 
em larga medida, era condição sine qua non para se demonstrar socialmente que se habitava o coração do seu senhor. Isto se traduzia em sinalizar para os demais concorrentes a qualidade e a dimensão do prestígio e do poder que se possuía. Enfim, em todas as experiências de valimento conhecidas durante o Antigo Regime, os favoritos tinham que conquistar primeiramente o afeto do rei.

As questões relativas aos afetos e à amizade foram objeto de reiteradas reflexões por parte dos letrados do período. Para eles, serviam como fontes de inspiração básica para a construção deste ethos social a tradição clássica e, obviamente, a Sagrada Escritura. No Antigo Testamento, por exemplo, encontravam-se inúmeros exemplos de como a benevolência, a fidelidade e os impulsos afetivos mais primordiais deveriam presidir toda a comunidade. Assim, qualquer gesto que atentasse contra estes princípios fundamentais atentava contra a própria comunidade como um todo. Portanto, a tradição cristã nada mais faria do que acentuar estas convicções assentadas na compreensão de que a sociedade era fruto do amor. ${ }^{34}$

No começo do século XVI, além da tradição bíblica e dos escritos dos grandes doutores da igreja, que enfatizavam o papel essencial dos afetos no ordenamento do mundo, talvez não houvesse letrado europeu que não conhecesse textos da tradição greco-romana em que, da mesma forma, a questão da amizade era mencionada com o intuito de destacar sua função como ordenadora da vida social. Além das obras de Platão e Aristóteles, às quais devemos guardar especial atenção por sua influência na Europa como um todo, principalmente no mundo Ibérico, temos as obras Da amizade, ${ }^{35}$ de Cícero, De como distinguir um adulador de um amigo, de Plutarco, e Dos benefícios, de Sêneca, textos cuja circulação durante a Época Moderna foi notadamente ampla, ${ }^{36}$ e se configuram

\footnotetext{
${ }^{34}$ Pedro Cardim, O Poder dos Afetos, op. cit., p. 53-55.

${ }^{35}$ A primeira versão deste texto para a língua portuguesa surgiu em 1531. A tradução foi realizada por Garcia Resende, recebendo o título Tratados de Amizade, paradoxos e sonho de scipio. Já em 1582, era publicado em Salamanca, com tradução de Francisco Támara e Juan Jarava, o Libro de Marco Tulio Cícero en que trata de los oficios, de la amicicia, de la senectud, añadiéndole ahora nuevamente las paradoxas y el sueño de Scipión. Estas duas obras são particularmente importantes para a Península Ibérica devido à sua grande circulação.

${ }^{36}$ Em fins do século XV já apareciam obras de Sêneca em línguas modernas. Em 1491, Alonzo de Cartagena, Bispo de Burgos (1384-1456), traduzia, e Meynardo Ungut Alimano e Stanislao Polono publicavam, em Sevilha, Cinco Libros de Séneca, cujo conteúdo era: 1. Dela vida bienaventurada, 2. Delas siete artes liberales, 3. De amonestamiento et doctrinas. 4. Reprimeto de providencia de Dio, 5. El segundo libro de providencia de Dios. Sobre a importância do estoicismo e de Sêneca para a filosofia e a cultura política moderna, ver Quentin Skinner, op. cit., p. 250-281.
} 
como os principais exemplos a serem mencionados. Através destes textos, a antigüidade greco-romana legou à posteridade a idéia de que as relações comunitárias se fincavam nos laços amistosos, e a vida em grupo se basearia na cooperação e na troca desinteressadas de bens e serviços. ${ }^{37}$

Em fins do mesmo século, na cultura humanista o debate em torno da questão da amizade foi bastante recorrente na filosofia do renascimento e esteve sempre presente na teoria política. Em um dos seus Essais, publicado pela primeira vez em 1580, intitulado justamente Da amizade, Montaigne, fazendo menção à moral aristotélica, dizia que a "amizade assinala o mais alto grau de perfeição da sociedade" ${ }^{38}$ Cerca de duas décadas depois, Francis Bacon (1561-1626) dedicou especial atenção à questão, procurando refletir sobre o significado da amizade no âmbito da constituição da sociedade e das relações políticas. Foi protegido e amigo de favoritos régios como Essex, Buckingham e Tobby Matthew. Em seus Essays, Civil and Moral, publicados entre 1597 e 1625 , podemos encontrar muitas reflexões acerca da amizade como fundamento para a construção do universo social e político, com destaque para Of Followers and Friends, de 1597, Of Friendship, de 1612, e outro pequeno texto, publicado em $1625,{ }^{39}$ que recebeu o mesmo título do anterior. Em todos estes textos, Bacon situa a problemática da amizade como elemento central na condução da vida política e social. O seu pensamento, enfim, torna-se perfeito exemplo daquilo que David Wootton definiu como um ponto de acesso privilegiado a este mundo perdido, no qual se confiava em fazer fortuna mediante favores e não salários; em que se buscava seu caminho na vida através da patronagem, não do mérito profissional, e onde se aspirava a estabelecer uma reputação duradoura através do elogio de amigos leais, não de críticos imparciais. ${ }^{40}$

No mundo ibérico, foram inúmeros os autores a tratar do assunto na escrita epistolar, no teatro, na teologia e na política. No início do quinhentos, Pedro Mexia escrevia que los hombres, por causa y respecto de los mismos hombres fueron formados y engendrados, y que asi nacieron obligados, a se ayudar e y aprouechar los unos a los otros, ${ }^{41}$ sendo que estes atos de entreajuda são neces-

\footnotetext{
${ }^{37}$ Pedro Cardim, O Poder dos Afetos, op. cit., p. 62.

${ }^{38}$ Michel de Montaigne, "Ensaios - I", Os Pensadores, São Paulo, Abril Cultural - Victor Civita, 1972, p. 96.

${ }^{39}$ Francis Bacon, "Essay, Civil and Moral", The Havard Classics, Nova Iorque, P. F. Collie \& Son Corporation, 1969, p. 7-144.

${ }^{40}$ David Wootton, "Francis Bacon: Vuestro Flexible Amigo", J. H. Elliott, Laurence Brockliss (orgs.), El Mundo de los Validos, op. cit., p. 266.

${ }^{41}$ Pedro Mexia, Silva de Varia Lección, Antuérpia, Martin Nucio, 1555, apud Pedro Cardim, O Poder dos Afetos, op. cit., p. 52.
} 
sariamente atitudes a provar a natural amizade que une os homens. Em 1605, Francisco Lobo Rodrigues, nas suas Éclogas, dizia que a "amizade he sancta \& boa, todo o bem Deos nella pos". ${ }^{2}$ Em um adágio, recolhido por António Delicado, em 1651, figurava a seguinte idéia: "A ley de Reynar, he como a de amar". ${ }^{43}$ Diego de Saavedra Fajardo, por sua vez, anotara pela mesma época que en todas las cosas animadas ó inanimadas vemos una secreta correspondencia y amistad. ${ }^{44}$ No Vocabulário, Bluteau assinalava que a "amizade" era o "vínculo da sociedade humana, sustento da vida civil, \& o bem por meyo do qual logrão os homens hum dos maiores prodígios do ser Divino a saber unidade com pluralidade, na perfeita união dos amigos", ${ }^{45}$ pois estes se ligavam um com o outro "pela uniformidade dos gênios, semelhança dos costumes, e mútua benevolência". ${ }^{46}$ Assim, através destas proposições, buscava-se legitimar a amizade como componente essencial da própria vida social, na qual se constituía, enfim, a cultura política. Ao lado de outras formas de organização da vida societária, os afetos desempenhavam um papel de destaque enquanto instrumento normativo e ordenador. A este respeito, novamente ouçamos o que Pedro Cardim tem a nos dizer.

$\mathrm{O}$ rei e aqueles que o rodeavam contavam com a normatividade do amor para manter a boa ordem (...) No período compreendido entre os séculos XV e XVIII vigorou uma comunidade ordenada mediante uma complexa e extremamente duradoura modalidade de organização, reconhecida e apoiada por uma série de focos de normatividade e por não menos numerosos mecanismos de regulação. Nessa ação simultaneamente ordenadora e disciplinadora destacava-se o poder dos afetos. ${ }^{47}$

Inerente a toda esta discussão sobre a importância dos afetos na constituição da sociedade, naquela cultura política, o modelo familiar era fundamental na própria estruturação de discursos legitimadores da importância da amizade. A relação entre pai e filho servia como princípio básico

\footnotetext{
${ }^{42}$ Francisco Rodrigues Lobo, Éclogas, Coimbra, Imprensa da Universidade, 1928, p. 87.

${ }^{43}$ António Delicado, “Adágios Portugueses Reduzidos a lugares comuns...”, Lisboa, Domingos Lopes Rosa, 1651, apud Pedro Cardim, O Poder dos Afetos, op. cit., p. 110.

${ }^{44}$ Diego de Saavedra Fajardo, "Idea un Príncipe Político-Cristiano, Representada en Cien Empresas", Obras de Don Diego Saavedra Fajardo (1ª ed., 1640), Madri, Real Academia Española / Atlas, 1947, p. 125.

${ }^{45}$ Pe. Raphael Bluteau, "Amizade”, op. cit., Tomo I, 1712, p. 340.

${ }^{46}$ Idem, "Amigo", p. 336-337.

${ }^{47}$ Pedro Cardim, O Poder dos Afetos, op. cit., p. 38.
} 
de identificação da amizade enquanto estrutura organizativa da sociedade. No plano simbólico, a relação entre pai e filho consubstanciaria a mais perfeita forma de amor e, portanto, de amizade, evidenciando o próprio caráter divino em que, a partir desta forma de amor, visto essencialmente no âmbito do sagrado, se produziria uma relação harmônica e perfeita. Surpreende-nos perceber que esta visão atravessou os séculos XVI e XVII, chegando ao XVIII praticamente "inalterada".

Perfazendo uma relação importante com isto que estamos discutindo, podemos dizer que a justaposição que existia entre as esferas da vida pública e privada funcionava como elemento importante, pois era a partir do modelo familiar que se imaginava e se buscava normatizar a própria vida comunitária, visto que esta era percebida como uma extensão da família. A historiadora italiana Daniela Frigo demonstrou o quanto, no universo da cultura letrada européia, a tratadística sobre a questão da administração doméstica foi importante para a construção do ethos aristocrático entre os séculos XVI e XVII, refletindo-se na própria compreensão que se estabeleceu sobre a gestão do governo. ${ }^{48}$ Sabemos que, na época, o primeiro e principal modelo de amizade e afeto que poderia existir entre os homens advinha justamente da relação entre pai e filho. Neste sentido, o fundamento básico de hierarquia e obediência encontrava-se na própria organização familiar e o pater familia era a própria expressão da autoridade legítima. Em nível mais geral, não é demais repetir, o rei era visto como o grande pai e senhor, protetor de todos. Para os validos, além destas funções, o rei era considerado a fonte de toda a graça e de todo o benefício afetivo possível. ${ }^{49}$

\footnotetext{
${ }^{48}$ Daniela Frigo, Il Padre di Famiglia. Governo della casa e governo civile nella tradizione dell' economica tra cinque e seicento, Roma, Bulzoni Editore, 1985, p. 17-63.

${ }^{49}$ Para além destas percepções acerca do lugar do rei na sociedade, havia toda uma construção simbólica pela qual o soberano foi percebido como representação da vontade de Deus entre os homens. Esta imagem foi uma das mais significativas construções da vida política do Antigo Regime. Algumas referências importantes sobre a problemática são: Marc Bloch, Os Reis Taumaturgos. O caráter sobrenatural do poder régio. França e Inglaterra, São Paulo, Companhia das Letras, 1993; Ernst Kantorowicz, Os dois corpos do rei. Estudo sobre Teologia Política Medieval, São Paulo, Companhia das Letras, 1998; Ralph E Giesey, Le Roi Ne Meurt Jamais. Les obsèques royales dans la France de la Renaissance, Paris, Flammarion, 1987; Sergio Bertelli, Il Corpo Del Re. Sacralità Del potere nell'Europa medievale e moderna, Florença, Ponte alle Grazie, 1995. Para uma síntese desta discussão, ver Jacqueline Hermann, No Reino do Desejado. A Construção do Sebastianismo em Portugal. Séculos XVI e XVII, São Paulo, Companhia das Letras, 1998, principalmente o capítulo III, "Da Monarquia Lusitana: a sacralidade do rei”, p. 125-176.
} 
Em síntese, pode-se dizer que o fenômeno do valimento se relaciona de maneira indissociável com a problemática dos afetos. No período, gozar do favor e da proteção de alguém mais poderoso e influente, senão do próprio Príncipe, constituía-se em elemento estruturante na corrida pelas oportunidades. E ser valido era ser, pretensamente, o amigo primeiro do rei. Significava estabelecer um laço, que, na maior parte dos casos, se configurava completamente informal, no que se conjugavam elementos básicos como amizade, lealdade, fidelidade e reciprocidade, sentimentos cujas raízes remontam à cultura medieval, a partir dos laços de suserania e vassalagem. ${ }^{50}$

A priori, esta relação deveria ser completamente desprovida de segundos interesses ou de objetivar ganhos pecuniários futuros. O que de fato se deveria sobrepor era a mais pura e límpida expressão da abnegação e da confiança entre as partes. Lembra Bartolomé Clavero que $e l$ ius amicitate era anterior a cualquer otro derecho, ${ }^{51}$ fundamentando-se no que se conhecia por graça. Ao rei cabia expressar sua gratidão por meio da liberalidade e de outras demonstrações de agradecimento pelos serviços prestados por seu melhor e mais destacado amigo. Em suma, pode-se dizer que o valido era "um dignitário que o rei escolhia como o seu mais próximo servidor, uma figura que também foi por diversas vezes designada como o melhor amigo do monarca". ${ }^{52}$

Mas, notemos que, nas diferentes línguas modernas, o conjunto de conceitos que identificavam o fenômeno do valimento eram enunciados e compreendidos a partir das questões que estamos abordando e, naquilo que poderíamos nomear por gramática da sociedade de corte, o entendimento acerca do lugar do valimento era bastante generalizado. O termo valido já havia sido empregado desde meados do século $\mathrm{XVI}^{53}$ no mundo ibérico, pois, de origem castelhana, a palavra passou a fazer parte do vocabulário corrente na época, como síntese para a idéia de alguém que se colocava sob a proteção de outro, bem mais poderoso. No Dictionarium Latino-Lusitanicum, et LusitanicoLatinum, o Pe. Jerônimo Cardoso assinalou dois sentidos para validus, palavra latina de onde derivou valido: o primeiro queria dizer "confirmar, ou fazer

\footnotetext{
${ }^{50}$ Renata Ago, La Feudalità In Età Moderna, Roma, Editori Laterza, 1994, p. 3-42, 97-160. Ver ainda Marc Bloch, A Sociedade Feudal, Lisboa, Ed. 70, 1987.

${ }^{51}$ Bartolomé Clavero, Antidora. Antropología Católica de la Economía Moderna, Milão, Giuffrè Editore, 1991, p. 192.

${ }^{52}$ Pedro Cardim, O Poder dos Afetos, op. cit., p. 469.

${ }^{53}$ Antônio Houaiss, no seu Dicionário da Língua Portuguesa, registra que o termo valido, no sentido que empregamos aqui, apareceu na língua portuguesa em torno de 1572, usado por Camões em Os Lusíadas.
} 
algua cousa", o segundo correspondia à valia, à privança, em sentido latino da idéia de gratiae. ${ }^{54}$ Tempos antes, o termo validus figurava no Dictionarium latino-gallicum, na versão publicada em 1552, do também humanista Robert Estienne, e significava fort et puissant, fort pour soustenir ${ }^{55}$ apontando para um sentido bastante próximo ao poder que se obtinha através do valimento de alguém mais poderoso e protetor.

No começo do século XVII, Sebastián de Covarrubias, apesar de sequer registrar o termo valido, anotou, por outro lado, que "favorecer" significava patrocinar e ayudar, sendo favorecido el que tiene favor, ${ }^{56}$ a partir de onde derivou o conceito de favorito. Mas o correspondente mais usual para valido na literatura coeva seiscentista - o conceito de privado - possuía uma dupla acepção: primeiramente aludia à idéia de privación, isto é, el que ha sido excluido de oficio o dignidad; e, em outra significação, correspondia à noção de privar, isto é, ser favorecido de algún señor, de privatus,a,um, cosa propia y particular, porque se particulariza con él y le diferencia de los demás; y este se llama privado, y el favor al señor le da privan: $a .^{57}$

A partir destas normatizações lexicais, realizadas por Covarrubias no universo da língua castelhana, cerca de um século mais tarde, o Diccionario de la Lengua Castellana registra que valido corresponde a firme, subsistente, y que vale, ù debe valer; equivalente a robusto, fuerte, ù esforsado ${ }^{58}$ o que a princípio parece não esclarecer muito. Contudo, o substantivo valimiento é bem mais próximo daquilo que estamos tratando, pois se associa à idéia de privan\&a, isto é, el favor, valimiento y trato familiar que el inferior tiene con el Principe o superior. ${ }^{59}$ Portanto, "valimiento" se toma también por privanza, ù aceptación particular de algún básalo por su Soberano, y por translación se dice de otras personas..$^{60}$ Por outro lado, na Espanha, não poucas vezes, evitava-se falar de privado ou valido, pois havia a possibilidade de estes termos serem tomados como pejorativos. Daí a insistência do Conde-Duque de Olivares, como vimos,

\footnotetext{
${ }^{54}$ Jerônimo Cardoso, "Validus", op. cit, p. 239-340.

${ }^{55}$ Robert Estienne, "Validus", Dicionarium Latinogallicum (1 ${ }^{\text {a }}$ ed., 1532), Lutetiae, Carolum Stephanum, 1552, p. 1349.

${ }^{56}$ Sebastián de Covarrubias, "Favorecer", op. cit., p. 586-587.

${ }^{57}$ Idem, "Privado", op. cit., p. 883.

${ }^{58}$ Real Academia Española, "Valido", op. cit., Tomo VI, 1739, p. 416.

${ }^{59}$ Idem, "Privanza", Tomo V, 1737, p. 385.

${ }^{60}$ Ibid, "Valimiento", Tomo VI, 1739, p. 416.
} 
favorito do rei Felipe IV, entre 1621-1640, em evitar ser publicamente chamado de valido ou privado, preferindo o termo Ministro. ${ }^{61}$

Em Portugal, no início do século XVIII, o Pe. Raphael Bluteau, no Vocabulário, por sua vez, definia valimento como favor, poder, amparo, mediania do valido. ${ }^{62}$ Dizia mais, o valido é "aquele que tem valimento, que pode com alguém mais do que os outros", ${ }^{63}$ o que aproxima o significado do vocábulo na língua portuguesa dos sentidos mais correntes na época em outras línguas. Entretanto, Bluteau procurou elaborar significados mais amplos para o vocábulo. Dizia: "são validos, olhos, \& orelhas do Príncipe, porque só por eles vem, \& ouvem os Príncipes". ${ }^{64}$ Fruto de uma cultura política assentada no favorecimento e nas chamadas redes clientelares, aspectos importantes de seu modus operandi, o fenômeno do valimento era coetaneamente compreendido como parte integrante da dádiva régia. Neste sentido, o valimento, segundo Bluteau, colocar-se-ia como pólo de concentração da graça e da benevolência régia, ou seja: "a graça de um Príncipe é um templo cuja porta são seus validos", já que estes "são os olhos e as orelhas do Príncipe, porque por eles os Reis vêem e ouvem tudo". ${ }^{65}$

Enfim, ao longo do setecentos, na língua de Camões, os termos continuariam sendo entendidos basicamente como havia sido registrado no Vocabulário de Bluteau. Pedro José da Fonseca, professor régio de retórica e poética em Lisboa, no Diccionario Portuguez, e Latino, obra publicada em 1771 e dedicada a El Rei D. José I, permanecia anotando que valido, cujos sinônimos privado e privança se confundiam, era aquele que desfrutava da aceitação e da boa amizade do Príncipe (Principem Gratiosus). ${ }^{66}$ Praticamente o mesmo entendimento teve António de Moraes Silva, destacada figura das letras luso-brasileiras de fins do século XVIII, em seu importantíssimo Diccionário da Língua Portuguesa, de 1789: o substantivo valido referia-se àquele

\footnotetext{
${ }^{61}$ John Elliott, Richelieu y Olivares, op. cit., p. 68-69. O conceito de ministro possuía fortes relações com o universo religioso, pois a idéia de ministro origina-se da de "ministro de Deus", ou seja, autoridades eclesiásticas. Os dicionários com os quais trabalhamos atestam isto.

${ }^{62}$ Pe. Raphael Bluteau, "Valimento", op. cit., Tomo IX, 1721, p. 354.

${ }^{63}$ Idem, "Valido", op. cit., Tomo IX, 1721, p. 354.

${ }^{64}$ Ibid, Tomo IX, 1721, p. 354.

${ }^{65}$ Ibidem, "Graça", Tomo III, 1713, p. 108.

${ }^{66}$ Pedro José da Fonseca, "Privança”, "Privado", "Valido", Diccionario Portuguez, e Latino, Lisboa, Régia Officina Typográfica, 1771, p. 577 e 714.
} 
"que tem valimento e privança de alguém", 67 e o adjetivo "poderoso" 68 traduzia a situação social alcançada pelo valimento, ou seja, "o merecimento, graça, privança, que se tem com alguém, em virtude da qual se consegue delle o desejado". ${ }^{9}$ Neste mesmo campo de significados, Moraes compreendia que o sinônimo para valimento, a chamada privança, se definiria por "valimento, trato, conversação do valido, e favorecido do Soberano; v.g. ter lugar na privança d'alguém, ter privança com alguém; i.e., privar com elle (...) amizade íntima, favor, benevolência". ${ }^{70}$

Saindo do mundo Ibérico, vemos que no Vocabolario Degli Accademici Della Crusca os termos valido e valimento já apareciam, mantendo-se, nas edições subseqüentes, significados semelhantes aos identificados nas línguas castelhana e portuguesa. Valido era, portanto, alguém "forte e poderoso": per lo tuo santo, e inessabile nome triforne per conseqüente il valido aiuto carced. Quindi aiutanto l'eremita dunque, ch'era della sua età valido, e forte. ${ }^{71}$ No entanto, a tradução mais próxima da idéia de valimento que se podia encontrar no universo das letras ibéricas era, sem dúvida, o conceito de "favorito", ou seja, che è in grazia, e favore d'alcuno, comumente s'intende di chi è in grazia de' grandi (...) Abbiti cura della invidia, la quale come palla di sapone, si mette sotto $i$ piede dei favoriti..$^{72}$

Na língua francesa, desde o início do século XVI, já havia o uso corrente da palavra favori, derivada de faveur, enunciando a situação do valimento. Mais tarde, Jean Nicot registra o termo no sentido de gratiosus, isto é, como alguém que guarda afeição, familiaridade e o amor de outro. ${ }^{73}$ Em sentido semelhante aparecem igualmente os significados de privé, ou seja,

(...) signifie familier, et comme domestique. Il se prend aussi pour secret, comme souvent aussi en Latin. Selon laquelle signification on dit, le Privé conseil du Roy, Secretum Regis Concilium. Et anciennement les Privez affaires du Roy, ce que à

\footnotetext{
${ }^{67}$ António de Moraes Silva, "Valido", Diccionario da Língua Portuguesa (1 $1^{\mathrm{a}}$ ed., 1789), Lisboa, Typografia Lacerdina, Tomo II, 1813, p. 828. (A edição consultada foi a facsimilar à de 1813, publicada em 1922).

${ }^{68}$ Idem, p. 828.

${ }^{69}$ Ibid, "Valimento", p. 828.

${ }^{70}$ Ibidem, "Privança", p. 505.

${ }^{71}$ Vocabolario degli Accademici della Crusca, "Valido", "Valimento", op. cit., Tomo V, 1746, p. 110 .

${ }^{72}$ Idem, "Favorito", Tomo II, p. 256.

${ }^{73}$ Jean Nicot, "Faveur", p. 280.
} 
present on appelle à la Cour, les affaires, sans addition de ce mot Privez: que est un Conseil du Roy plus estroict, et plus secret que le Privé dessusdit du Roy. ${ }^{74}$

Entretanto, o termo favori, a partir do qual se derivou o substantivo favorite, expressava a idéia de que se tratava daquela pessoa que tient le premier rang dans la faveur, dans les bonnes graces d'un Roy, d'un grand Prince, d'une grand Reine, d'une grande Princesse, conforme se pode averiguar no Dictionnaire de L'Academie Française, já na primeira edição de $1694 .{ }^{75}$ Todavia, em sentido muitas vezes explicitamente negativo, havia também na língua francesa a palavra mignon, a expressar uma maneira específica de valimento, no caso, quase sempre associado a conotações sexuais. Assim se pode ver tanto no Thresor, de Nicot, quanto no Dictionnaire de L'Académie. ${ }^{76}$ Por outro lado, na França do Cardeal Richelieu, tal como na Espanha de Olivares, evitava-se usar nos discursos políticos oficiais expressões como favorite ou mignon, vistas como formas depreciativas de obtenção da graça régia. Afirmava-se, sim, o conceito de ministre, em grande medida porque Richelieu insistiu em empregar o termo para designar as suas funções junto à governação, como uma forma mais "institucional" de definir seu estatuto. Algo semelhante parece ter acontecido durante a privança de Olivares na Espanha, quando este também procurou evitar no plano oficial os conceitos de valido ou privado, insistindo em dizer-se ministro. Contudo, a premissa básica do valimento continuava existindo, pois estes ministres foram sempre dependentes da graça régia. Ao que parece, o título de primeiro-ministro só foi utilizado oficialmente a partir de 1659, quando se assinou o Tratado dos Pirineus, entre Espanha e França. Mazarino e Luis Haro, que, respectivamente, sucediam aos valimentos de Richelieu e Olivares, na ocasião foram nomeados primeros y principales ministos de sus reyes. ${ }^{77}$

É interessante notar ainda que, no âmbito da língua inglesa, Samuel Johnson, no Dictionary of the English Language, publicado pela primeira vez em 1755, definiu os termos Privado, isto é, secret friend e Favourite, que se definia por a person or thing beloved, one regarded with favour; one chosen

\footnotetext{
${ }^{74}$ Idem, "Privé", p. 513.

${ }^{75}$ Dictionnaire de L'Académie, "Favori, ite, s", op. cit., Tome I, 1694, p. 724.

${ }^{76}$ Jean Nicot, "Mignon”, op. cit., p. 411; Dictionnaire de L'Académie, op. cit., Tome II, p. 142.

${ }^{77}$ John H. Elliott Richelieu y Olivares, op. cit., p. 69; Francisco Tomas y Valiente, op. cit., Apéndice IX, p. 185 e segs.
} 
as a compassion by his superior ${ }^{78}$ correspondendo ao conteúdo relacionado à situação de valimento. Ao longo do século XVII, os dois conceitos eram amplamente usados para expressar basicamente a mesma coisa. Francis Bacon, em seu ensaio Of Friendship, havia demarcado: the modern languages give unto such persons the name of favorites, or privadoes; as if it were matter of grace, or conversation. ${ }^{79}$ Entretanto, ao que tudo indica, entre os letrados ingleses do Antigo Regime predominou o termo favorito (favourite) como forma de identificar o fenômeno do valimento na cultura política coetânea. ${ }^{80}$

O certo é que o valimento, enquanto fenômeno particular da cultura política do Antigo Regime, pode ser definido como um conceito que se inscrevia no universo da graça, isto é, no âmbito dos significados das relações sociais de amizade no Antigo Regime, as quais, por sua vez, se situam na dimensão social do que Bartolomé Clavero nomeou por antidora, ${ }^{81}$ ou seja, no universo simbólico da graça e da reciprocidade entre as pessoas que compõem o corpo social. Inerente àquilo que se conheceu como don, gift, dono, gabe e grace na semântica das sociedades do Antigo Regime, pode-se definir esta relação pela fórmula seguinte: aquilo que se dá espontaneamente e se recebe legitimamente "é um recíproco gratis dans, o intercâmbio de doações teoricamente desinteressadas". ${ }^{82}$ Jerônimo Cardoso, ao definir o significado gratiae nudae, isto é, "graça nua", "graça pura", marcava que "as boas obras hão de ser sem interesse". ${ }^{83} \mathrm{O}$ Pe. Raphael Bluteau anotou que "Antidorum he palavra de origem grega composta de Doron, que quer dizer donativo, ou dádiva, etc. E da preposição anti, \& assim Antidorun quer dizer dádiva em agradecimento de outra (...)" ${ }^{84}$

\footnotetext{
${ }^{78}$ Samuel Johnson, Dictionary of the English Language In which the words are deduced from their originals, and illustrated in their different significations by examples from the best writers. To which are prefixed, a history of the language, and an English grammar, Londres, W. Strahan, Vol. II, 1755, p. 153-154.

${ }^{79}$ Francis Bacon, op. cit., p. 67.

${ }^{80}$ A historiadora Linda Levy Peck realizou um estudo abrangente e profundo sobre o contexto, as linguagens, as representações, as configurações, a corrupção e as conseqüências do favoritismo régio na Inglaterra do século XVII. Ver Linda Levy Peck, Court Patronage and corruption in Early Stuart England, Londres, Routledge, 1993.

${ }^{81}$ Bartolomé Clavero, Antidora, op. cit., p. 15.

${ }^{82}$ Idem, p. 16.

${ }^{83}$ Jerônimo Cardoso, "gratiae nudae”, op. cit., p. 79.

${ }^{84}$ Pe. Raphael Bluteau, “Antidorum”, op. cit., Tomo I, 1712, p. 403.
} 
Neste ponto, vale recordar que as reflexões que foram feitas no âmbito da antropologia cultural por Marcel Mauss, em seu clássico Ensaio sobre a Dádiva, publicado pela primeira vez entre os anos de 1923-1924, já identificara esta estrutura relacional nas transações de troca - materiais e simbólicas - das sociedades arcaicas. A partir da compreensão de que estas práticas funcionavam como "fenômenos sociais totais", Mauss percebia nelas elementos estruturantes para tais sociedades. Estas relações, que se estabeleciam com base no ato de dar, visto como aparentemente desinteressado e descompromissado, fruto da amizade, eram na verdade repletas de princípios de obrigatoriedade e interesse. ${ }^{85}$ Conforme observou António Manuel Hespanha, o estudo de Mauss ultrapassou em muito a dimensão específica das sociedades exóticas da Polinésia, pois esta estrutura de dar, receber e restituir pode ser encontrada em sociedades pré-industriais em geral, sendo particularmente importante no que se refere às sociedades européias desde a antigüidade até o Antigo Regime. Os atos que são naturalmente gratuitos conformam um "universo normativo minucioso e precioso" ${ }^{86}$ configurando aquilo que pode ser nomeado como "a economia dos atos gratuitos". ${ }^{87}$

Em síntese, poderíamos dizer que fazia parte da lógica das sociedades do Antigo Regime a compreensão de que a entreajuda desinteressada, pelo menos no discurso, somada à liberalidade e a críticas veementes a qualquer prática de acumulação pecuniária não natural, se constituiria em verdadeiro fundamento acerca da forma como se compreendiam o mundo e as próprias relações sociais. ${ }^{8}{ }^{8}$ Desta forma, intrínsecas à estrutura cultural que acompanhou as sociedades européias no Antigo Regime, por meio de conceitos como amizade, liberalidade, caridade, magnificência, gratidão e serviço, estas formas de vinculação político-social se instituíram longevamente e se tornaram elementos importantes, em especial nas regiões notadamente católicas. ${ }^{89}$ Lembra Maria Fernanda de

${ }^{85}$ Marcel Mauss, "Ensaio sobre a Dádiva. Forma e Razão da troca nas sociedades arcaicas”, Sociologia e Antropologia, São Paulo, Casac \& NAIFY, 2003, p. 185-314.

${ }^{86}$ António Manuel Hespanha, La Gracia del Derecho. Economía de la cultura en la Edad Moderna, Madri, Centro de Estudios Constitucionales, 1993, p. 154 e segs.

${ }^{87}$ Idem, p. 156.

88 Ângela Barreto Xavier, António Manuel Hespanha, "As Redes Clientelares. A Economia do Dom. Amizades e Clientelas na Ação Política", José Mattoso (dir.), António Manuel Hespanha (coord.), História de Portugal. O Antigo Regime (1620-1807), Lisboa, Estampa, 1992, p. 381-393.

${ }^{89}$ António Manuel Hespanha, La Gracia del Derecho, op. cit., p. 157 e segs; Bartolomé Clavero, Antidora, op. cit. 
Olival que "a liberalidade régia", isto é, o gesto de dar, era uma atribuição própria dos reis, uma de suas prerrogativas fundamentais. ${ }^{90}$ A este respeito, dizia o Pe. Raphael Bluteau: "Em nenhuma cousa mais se parecem os Monarcas com Deos, que em dar". 91

Nesta perspectiva, e para o que aqui nos interessa, relações de valimento são, do ponto de vista político, exemplos privilegiados da "economia dos afetos" que organizava a vida social no Antigo Regime. Desta forma, o fenômeno do valimento se inscrevia em um processo complexo de disputa, acima de tudo pelo monopólio da amizade e do amor régio, ápice da cadeia de sucessos necessários para a ascensão social e política. A este respeito, já chamara atenção Francisco Tomas y Valiente em sua clássica obra sobre os validos, em que afirmava: $e l$ valido conquista con amabilidad y astucia - con servilismo si es preciso-la voluntad del Rey (...) El valido es el amigo del Rey, solo en el se apoya (..... ${ }^{92}$

Todavia, a compreensão sobre o que era a "amizade" variava. Na esfera da alta aristocracia, predominava uma concepção notadamente centrada na dimensão familiar e de confiança mútua entre as partes, cujo objetivo básico seria promover o bem comum. Como assinala Pedro Cardim, para este segmento da sociedade vigorava o entendimento de que a verdadeira "amizade" era a desprovida de segundas intenções, em sentido "antidoral", ou seja, da expectativa de troca ou possibilidade de ganho através de um sentimento. Por outro lado, em oposição a este entendimento sobre o lugar da amizade como elemento da cultura política, afirmava-se cada vez mais a noção de laços de afetividade individualistas e voluntaristas, ou seja, a abertura necessária para a afirmação do valimento enquanto fenômeno de concentração da afetividade e da graça régia. ${ }^{33}$

Portanto, colocando-se como pólo de concentração da graça e da benevolência régia, como sintetizou John Elliott, o valido era um homem que alcançou proeminência mediante a captação do poder real e pelo domínio de sua vontade. ${ }^{94} \mathrm{~A}$ origem dos validos é diversa e elementos oriundos tanto da alta aristocracia quanto de lugares inferiores da hierarquia social vivenciaram

\footnotetext{
${ }^{90}$ Ver Maria Fernanda de Olival, Honra, Mercêe Venalidade, Évora, Universidade de Évora, 1999, p. 25 e segs. (Tese de doutorado).

${ }^{91}$ Pe. Raphael Bluteau, "Liberal”, op. cit., Tomo V, 1716, p. 79.

${ }^{92}$ Francisco Tomas y Valiente, op. cit., p. 32.

${ }_{93}$ Pedro Cardim, O Poder dos Afetos, op. cit., em especial o capítulo VI, "Amizade, familiaridade e confiança política", p. 394-475.

${ }^{94}$ John H. Elliott, Richelieu y Olivares, op. cit., p. 49-50.
} 
a experiência do valimento. Quase sempre o fato de terem sido, durante os tempos de juventude do futuro monarca, príncipe ou governador, uma pessoa próxima e influente abria caminho para o valimento. Do ponto de vista de uma sociologia dos afetos, conforme já apontamos, o valimento surgia então a partir de relações pessoais tecidas entre um jovem príncipe, inseguro e aberto a amizades, e alguém mais velho que, quando não era o próprio tutor responsável pela educação do príncipe, se configurava na pessoa mais próxima e influente. Havia ainda os validos acusados de serem favorecidos devido a relações íntimas e de caráter sexual com os príncipes, o que os tornaria os mais próximos. Entretanto, não podemos esquecer que, nestas configurações sociais, tais práticas estavam legitimadas pela própria natureza das monarquias modernas, nas quais inexistia a separação das esferas pública e privada.

O caráter pessoal das relações era, portanto, a regra do modus operandi destas sociedades. Assim, o valimento inscrevia-se na própria demanda específica da estruturação política do Antigo Regime como espaço possível para a hegemonia de um grupo aristocrático sobre os demais, ou mesmo como forma de ascensão para sujeitos oriundos de setores não nobilitados da sociedade, em geral letrados, que, por méritos e serviços diversos, obtinham a graça régia. Contudo, era essencial a amizade que se desenvolvia entre ambas as partes, regidas por um complexo código nos quais os afetos possuíam o poder de agir como elementos importantes no processo de coesão social.

Do ponto de vista da moral religiosa, que funcionava como um dos elementos básicos de normatização e de coesão social, alertava Bluteau que a "graça do Rei não é donativo de fortuna, é vontade de Deus, que nos olhos do Soberano, quando vê o vassalo excita uma certa inclinação e propensão de afeto para ele", ${ }^{95}$ ou seja, sendo parte integrante da liberalidade régia, o atributo da graça do valimento fazia parte do próprio ordenamento natural criado por Deus, o que implicava uma postura de humildade e devoção cristã por parte daquele que privasse deste gesto de benevolência. A concepção da graça de valimento, definida por Bluteau, é um importante registro da amplitude social em que se inscrevem tanto os juízos coevos, favoráveis à presença de validos junto ao Rei, como os que faziam sérias críticas ao valido. Vejamos novamente o que nos fala o Vocabulário.

${ }_{95}$ Pe. Raphael Bluteau, "Graça", op. cit., Tomo III, 1713, p. 108. 
Donde se segue, que os que logrão a Graça do Príncipe, não hão de atribuir este favor à fortuna, mas a Deos, \& não se hão de valer do ditto favor para própria estimação, mas para fazer bem a todos, para moderar a indignação do Príncipe, para lhe fazer presente a crueldade dos ministros, para sollicitar a remuneração dos beneméritos; $\&$ com esta caridade, $\&$ benevolência, não só não será envejado, mas querido de todos, \& considerado como intecessor, $\&$ medianeiro de todos os bons despachos. A quem está na graça do Príncipe, ou justa, ou injustamente, he necessário abaixar a cabeça. Ela, (como dizem os legisladores) he ímpeto de potencia superior, a que nenhuma autoridade inferior pode resistir. ${ }^{96}$

Em suma, como tentamos demonstrar, na cultura política do Antigo Regime, era condição sine qua non para qualquer ambição de sentido ascensional possuir algum valimento de alguém mais poderoso e forte, sendo objetivo comum a todos os cortesãos atingir o coração da graça régia. Como bem caracterizou Elias, o clima de disputas e concorrências pelo prestígio na Corte de Luís XIV tornava a tessitura social da elite aristocrática algo que oscilava incessantemente, pois o equilíbrio no seio dessa sociedade era muito instável. ${ }^{97}$ Neste sentido, a busca do valimento pode ser pensada enquanto um grande drama, no qual a insegurança era a realidade do jogo. Eis, talvez, a maior ambigüidade que comportava a graça do valimento, porque, por mais que fosse institucionalizado o papel desempenhado por um personagem que possuísse valimento, em última instância o que determinava seu poder era o afeto de alguém poderoso e, da mesma forma, o desafeto do mesmo significava, na maior parte dos casos, o fim de uma trajetória política.

${ }^{96}$ Idem, p. 108.

${ }^{97}$ Norbert Elias, A Sociedade de Corte, Rio de Janeiro, Jorge Zahar Editor, 2001, p. 108. 